University of Nebraska - Lincoln

DigitalCommons@University of Nebraska - Lincoln

Hydrogeophysical Investigations at Hidden Dam, Raymond, California

\author{
Burke J. Minsley \\ U.S. Geological Survey, bminsley@usgs.gov \\ Bethany L. Burton \\ U.S. Geological Survey, Denver, blburton@usgs.gov \\ Scott lkard \\ Colorado School of Mines \\ Michael H. Powers \\ U.S. Geological Survey, Denver
}

Follow this and additional works at: https://digitalcommons.unl.edu/usgsstaffpub

Part of the Earth Sciences Commons

Minsley, Burke J.; Burton, Bethany L.; Ikard, Scott; and Powers, Michael H., "Hydrogeophysical Investigations at Hidden Dam, Raymond, California" (2011). USGS Staff -- Published Research. 517. https://digitalcommons.unl.edu/usgsstaffpub/517

This Article is brought to you for free and open access by the US Geological Survey at DigitalCommons@University of Nebraska - Lincoln. It has been accepted for inclusion in USGS Staff -- Published Research by an authorized administrator of DigitalCommons@University of Nebraska - Lincoln. 


\title{
Hydrogeophysical Investigations at Hidden Dam, Raymond, California
}

\author{
Burke J. Minsley ${ }^{1}$, Bethany L. Burton ${ }^{1}$, Scott Ikard $^{2}$ and Michael H. Powers ${ }^{1}$ \\ ${ }^{1}$ Crustal Geophysics and Geochemistry Science Center, U.S. Geological Survey, Denver, Colo. 80225 \\ Email: bminsley@usgs.gov \\ ${ }^{2}$ Colorado School of Mines, Department of Geophysics, Golden, Colo. 80401
}

\begin{abstract}
Self-potential and direct current resistivity surveys are carried out at the Hidden Dam site in Raymond, California to assess present-day seepage patterns and better understand the hydrogeologic mechanisms that likely influence seepage. Numerical modeling is utilized in conjunction with the geophysical measurements to predict variably-saturated flow through typical two-dimensional dam cross-sections as a function of reservoir elevation. Several different flow scenarios are investigated based on the known hydrogeology, as well as information about typical subsurface structures gained from the resistivity survey. The flow models are also used to simulate the bulk electrical resistivity in the subsurface under varying saturation conditions, as well as the self-potential response using petrophysical relationships and electrokinetic coupling equations.

The self-potential survey consists of 512 measurements on the downstream area of the dam, and corroborates known seepage areas on the northwest side of the dam. Two directcurrent resistivity profiles, each approximately $2,500 \mathrm{ft}(762 \mathrm{~m})$ long, indicate a broad sediment channel under the northwest side of the dam, which may be a significant seepage pathway through the foundation. A focusing of seepage in low-topography areas downstream of the dam is confirmed from the numerical flow simulations, which is also consistent with past observations. Little evidence of seepage is identified from the self-potential data on the southeast side of the dam, also consistent with historical records, though one possible area of focused seepage is identified near the outlet works. Integration of the geophysical surveys, numerical modeling, and observation well data provides a framework for better understanding seepage at the site through a combined hydrogeophysical approach.
\end{abstract}

\section{Introduction}

Geophysical field investigations, supported by coupled hydrogeophysical modeling, have been carried out at the Hidden Dam in Raymond, California for the purpose of better understanding the hydrogeology and seepage-related conditions at the site. Known seepage areas on the northwest right abutment area of the downstream side of the dam are documented by Cedergren (1980a, 1980b). Subsequent to the 1980 seepage study, a drainage blanket with a subdrain system was installed to mitigate downstream seepage. Flow net analysis provided by Cedergren (1980a, 1980b) suggests that the primary seepage mechanism involves flow through the dam foundation caused by normal reservoir pool elevations, which results in upflow that intersects the ground surface in several areas on the downstream side of the dam. In addition to the reservoir pool elevation and downstream surface topography, flow is also controlled by the existing foundation geology as well as the presence or absence of a horizontal drain within the downstream portion of the dam.

The purpose of the current geophysical work is to (1) identify present-day seepage areas that may not be evident because of the effectiveness of the drainage blanket in redirecting seepage water, and (2) provide information about subsurface geologic structures that may control subsurface flow and seepage. These tasks are accomplished through the use of two complementary electrical geophysical methods, self-potentials (SP) and direct-current (DC) electrical resistivity, which have been commonly used in dam seepage and other integrated hydrogeologic studies (Berube, 2007; Bogoslovsky and Ogilvy, 1970a, 1970b; Bolève et al., 2009; Corwin, 2007; Dahlin et al., 2008; Ogilvy et al., 1969; Panthulu et al., 2001; Sheffer, 2007; Sjödahl et al., 2005, 2008; Titov et al., 2005). SP is a passive method that is 
Journal of Environmental and Engineering Geophysics

primarily sensitive to active subsurface groundwater flow and seepage, whereas DC resistivity is an activesource method that can provide information about changes in subsurface lithology and groundwater saturation. Together, these methods can provide insight into both active seepage patterns, as well as subsurface lithology and structures that may control seepage.

The focus of this study is on seepage through the foundation in the downstream area on the right abutment, or northwest side of the dam. Seepage through the embankment materials is not addressed here, as data acquisition over the embankment riprap materials was not undertaken because of logistical difficulties in acquiring and interpreting these data (e.g., Sjödahl et al., 2006). The geophysical surveys were located primarily on the downstream right side of the dam, though two self-potential profiles also extended over the entire downstream length of the dam.

Integrating numerical simulations of variably saturated flow through the dam with the geophysical surveys and observation well data from the site provides a mechanism for better understanding the primary hydrogeologic controls on seepage through a coupled hydrogeophysical approach (Ferré et al., 2009). In this study, the hydrogeologic models are constrained by the results of the resistivity survey, and are used to predict the self-potential response by incorporating electrokinetic coupling into the numerical simulations (Jardani et al., 2008; Sill, 1983; Titov et al., 2002). By comparing the results of the numerical simulations with observed geophysical and hydraulic data from the site, inferences about the likely hydrogeologic model can be updated in order to better match observations. Future efforts will focus on a more rigorous integrated hydrogeophysical interpretation, where geophysical data are more directly incorporated into the dynamic estimation of hydrogeologic parameters (Bauer-Gottwein et al., 2010; Ferré et al., 2009; Hinnell et al., 2010).

\section{Site Background}

\section{Location and Geology}

Hidden Dam is located on the Fresno River in the Sierra Nevada foothills, approximately 15 miles northeast of Madera, California (Fig. 1). Detailed information regarding the dam construction and local geology and hydrology, summarized below, is provided by the U.S. Army Corps of Engineers (1977) and Cedergren (1980a, 1980b). Hidden Dam is a rolled earthfill dam constructed between 1972 and 1975, with a crest length of approximately $5,700 \mathrm{ft}(1,737 \mathrm{~m})$ and a maximum height above streambed of $184 \mathrm{ft}(56 \mathrm{~m})$ and a crest elevation of $561 \mathrm{ft}(171 \mathrm{~m})$. At gross pool (elevation of $540 \mathrm{ft}(165 \mathrm{~m}))$, the impounded lake has a surface area of about 1,570 acres $\left(6.35 \mathrm{~km}^{2}\right)$ and a storage capacity of 90,000 acre-feet $\left(0.11 \mathrm{~km}^{3}\right)$. Relief at the dam site is approximately $180 \mathrm{ft}(55 \mathrm{~m})$ with elevations ranging between around $400 \mathrm{ft}(122 \mathrm{~m})$ at the streambed to approximately $580 \mathrm{ft}(177 \mathrm{~m})$ on the right and left abutments. This topography is characterized by gently rolling, rounded hills with scattered rock outcrops.

The area in the vicinity of Hidden Dam is underlain by what is generally described as granitic and associated metamorphic rocks derived from the Sierra Nevada batholith (Bateman et al., 1963), though there is some variability in composition, texture, and color. Granitic rocks are overlain by residual soil, slope wash, and alluvium, ranging in thickness from zero to approximately $30 \mathrm{ft}(9 \mathrm{~m})$ and varying in composition between sands, silts, and clays. Beneath the overburden, to total depths up to approximately $60 \mathrm{ft}(18 \mathrm{~m})$, the granite is decomposed such that it is easily crumbled or broken. More competent rock occurs below the decomposed granite, though decomposed materials are occasionally interspersed up to depths of $140 \mathrm{ft}$ (43 m). Jointing was observed throughout the foundation area during excavation, though the profusion of joints and the extent to which they are clay-filled varies throughout the site.

\section{Right Abutment Seepage Area}

Known seepage in the right abutment area of the dam was the focus of studies by Cedergren (1980a, 1980b). Observations obtained from sixteen piezometers initially installed at the dam site, plus fourteen additional observation wells (Fig. 1), showed significant subsurface pressures (several with a piezometric surface higher than the ground surface) at a pool elevation of $484 \mathrm{ft}(148 \mathrm{~m})$ during the 1980 study. Flow nets calibrated to the observation well data suggested that very high uplift pressures could be expected at gross pool, potentially leading to erosion in the foundation. Flow nets also confirmed that low-topography areas on the downstream side of the dam are focal points for seepage through the foundation. Additional observation wells and piezometers were installed at the site based upon recommendations from the 1980 seepage study, and have been monitored on a monthly basis. Also, a drainage blanket with a sub-drain system was installed over much of the right abutment area of the dam to rapidly drain seepage in this area.

Figure 2 shows the reservoir elevation during the past ten years, which tends to reach a minimum in September-October, then begins to rise rapidly around January, peaking in April-June before declining again. Elevation gains in a typical year seem to be approximately $40-50 \mathrm{ft}(12-15 \mathrm{~m})$, though gains of $90 \mathrm{ft}$ $(27 \mathrm{~m})$ and $10 \mathrm{ft}(3 \mathrm{~m})$ were seen in 2005 and 2007, 


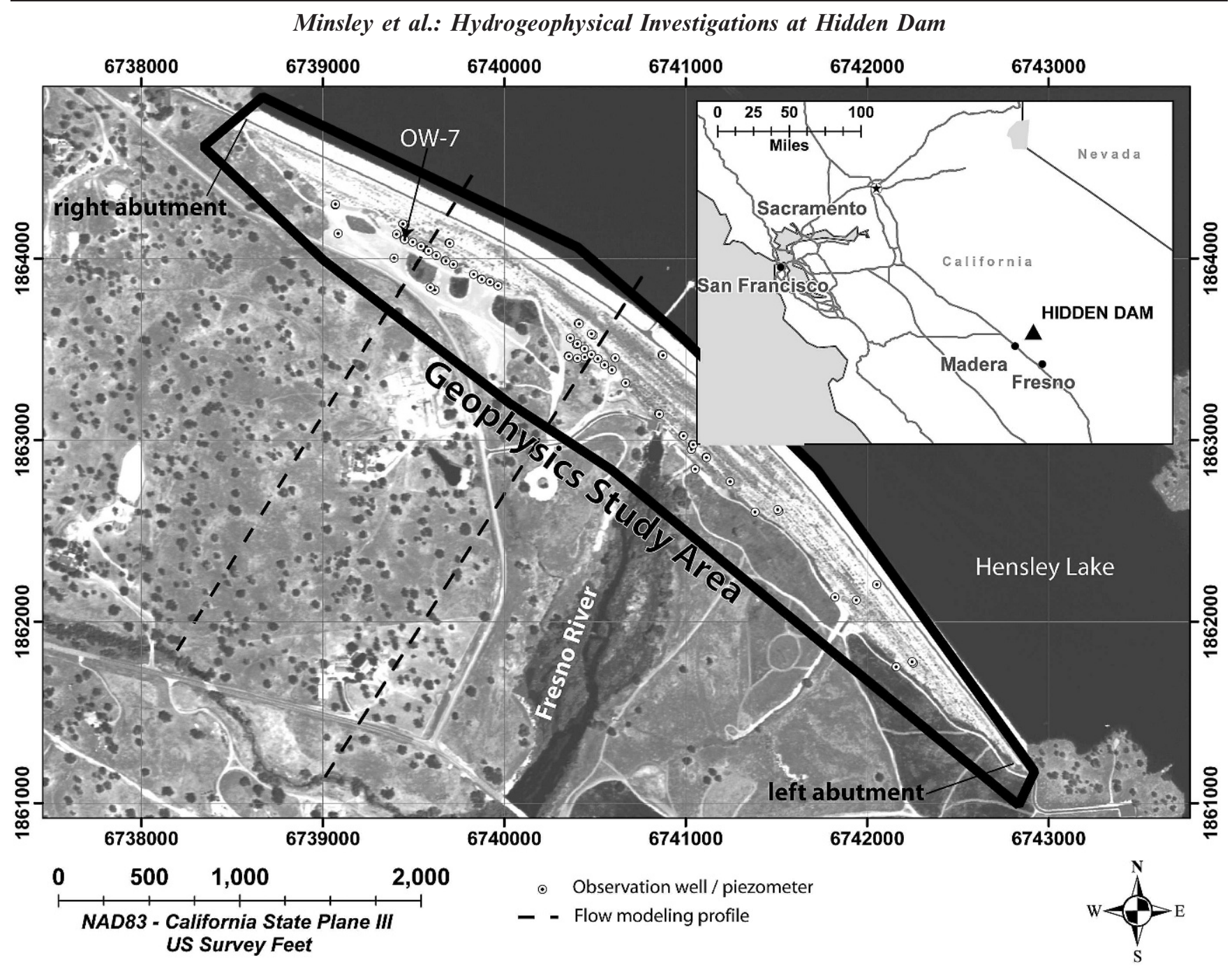

Figure 1. Location (inset) and aerial photo of Hidden Dam indicating the study area for this report. Distances in meters equal 0.3048 times distances in feet.

respectively. Reduced seepage is expected between September and January when the reservoir elevation is typically near or below $470 \mathrm{ft}(143 \mathrm{~m})$, while higher reservoir elevations, and increased seepage, are observed throughout the remainder of the year. Elevations from early 2005 to mid 2007 were atypical for this period, with the minimum reservoir elevation near $500 \mathrm{ft}$ $(152 \mathrm{~m})$. The present geophysical survey was scheduled for early May to coincide with the seasonal maximum reservoir elevation, and therefore the greatest potential for seepage, though the 2009 high pool reservoir elevation only reached approximately $490 \mathrm{ft}(149 \mathrm{~m})$. This elevation is relatively low, though still higher than the $484 \mathrm{ft}(147.5 \mathrm{~m})$ level recorded during the 1980 seepage study. Because the self-potential method is sensitive to active seepage, it is important to record these data during a period when seepage is expected to occur.

\section{Geophysical Surveys}

\section{Self-potential}

The self-potential method measures the naturally occurring electrical potential on the earth surface caused by subsurface current sources (Sill, 1983). One of the primary sources of self-potential signals is fluid flow in porous media, such as groundwater flow or seepage through a dam. An excess positive charge that develops near grain surfaces in saturated porous geologic media is transported along with the fluid, creating a streaming current density. This subsurface electrokinetic phenomenon generates a balancing conduction current density, which flows through the earth resistivity structure and is manifested as the measurable self-potential on the earth surface (Ishido and Mizutani, 1981; Morgan et al., 1989; Revil et al., 1999; Sill, 1983). The degree of coupling between fluid and electrical flows varies with fluid and rock chemistry, but is generally 
Journal of Environmental and Engineering Geophysics

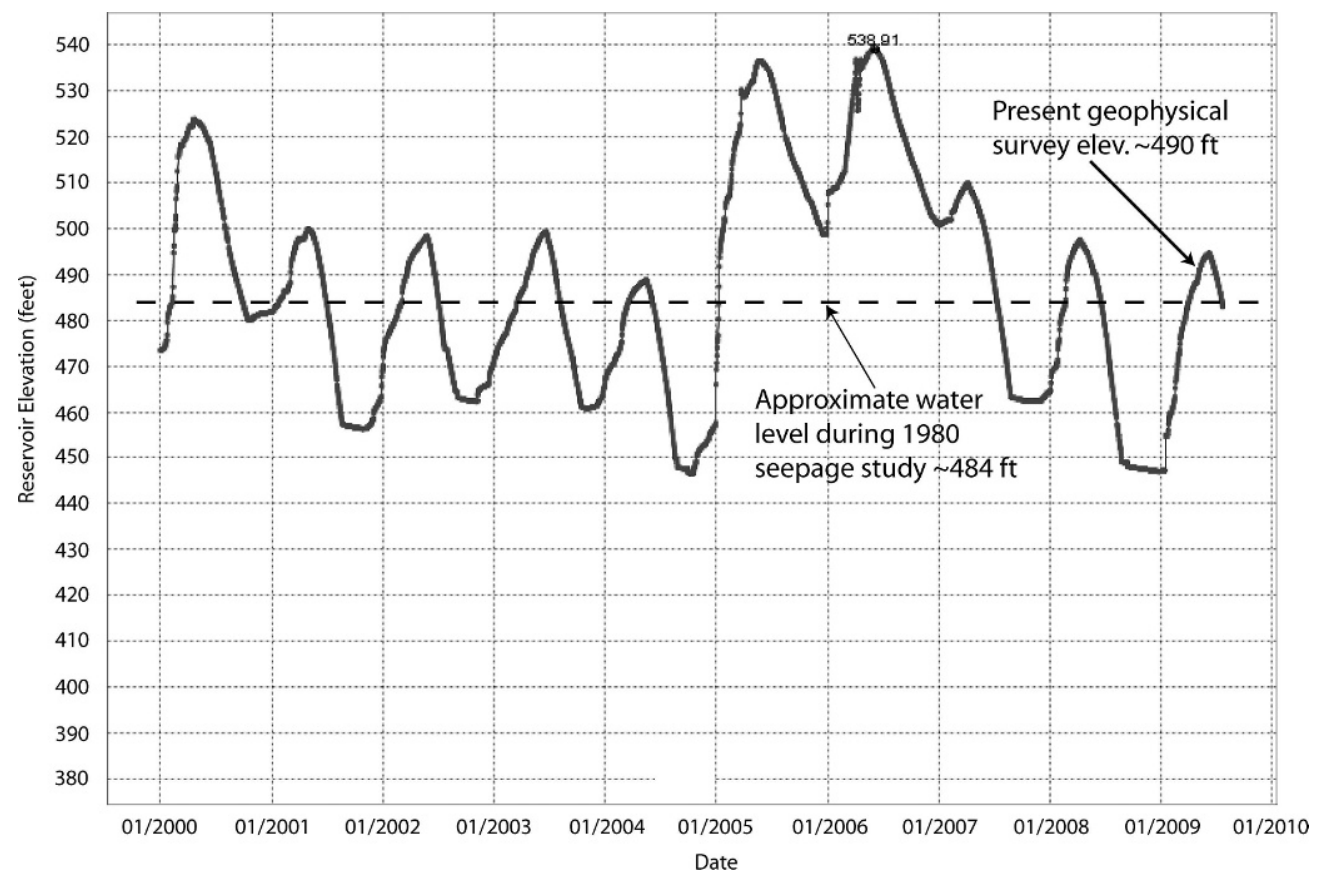

Figure 2. Hidden Dam reservoir elevation from January 1999 through July 2009 from the California Department of Water Resources Data Exchange Center (http://cdec.water.ca.gov/). Water levels during the 1980 seepage study (Cedergren, 1980a) and the present geophysical survey are annotated. Elevations in meters equal 0.3048 times elevation in feet.

such that the electrical potential gradient is in the opposite direction of the hydraulic gradient. That is, increasingly positive self-potentials are typically measured in the direction of fluid flow (or decreasing hydraulic head). A seepage-related self-potential signal would therefore be positive in the downstream/outflow area, and more negative in the upstream/infiltration area. In rare cases of unusual rock-fluid chemistry, the hydraulic-electric coupling can take on an opposite sign (Morgan et al., 1989), but this is not expected at the Hidden Dam site, nor is it supported by the measured data.

Self-potential measurements were made using the reference electrode method, whereby the electrical potential is measured between a fixed base electrode and a roving electrode connected to a long spool of wire (approximately 2,500 ft $(762 \mathrm{~m})$ ). Non-polarizing lead/lead chloride electrodes, fashioned after the Petiau electrode (Petiau, 2000), were used for all self-potential measurements. At each station, three shallow holes were dug and filled with a small amount of salted bentonite mud to improve electrical contact with the earth in the generally dry and gravelly conditions found at the site. Five self-potential measurements were recorded in each of the three holes, for a total of 15 measurements per station, using an Agilent U1252A ${ }^{1}$

\footnotetext{
${ }^{1}$ Any use of trade, product, or firm names is for descriptive purposes only and does not imply endorsement by the U.S. Government.
}

high impedance digital voltmeter and laptop computer with data logging software. Each station was assigned a unique identifier to facilitate further processing, and locations were recorded with a handheld global positioning system (GPS) unit.

A total of 512 self-potential stations were acquired, primarily along several lines that parallel the downstream toe of the dam (Fig. 3), though several other transects were also surveyed in areas of interest including one line in the reservoir on the upstream side of the dam. Individual lines of data were collected by spooling out the roving electrode at $40 \mathrm{ft}(12 \mathrm{~m})$ intervals (nominal station spacing) along the line from the base electrode location. A new base electrode location was established for each line, and individual lines of data have been tied together by measuring the self-potential between base stations on adjacent lines, as well as occupying the same station where lines intersected. Electrode drift was checked at the beginning and end of each line by placing both electrodes in a bucket of saline water and measuring their potential difference, which was generally less than $1 \mathrm{mV}$.

The use of salted bentonite mud in each hole has been found to improve measurement quality in dry and rocky locations such as Hidden Dam where poor electrical contact with the ground can degrade signal quality. This practice was used throughout the entire survey, resulting in significantly lower contact resistanc- 


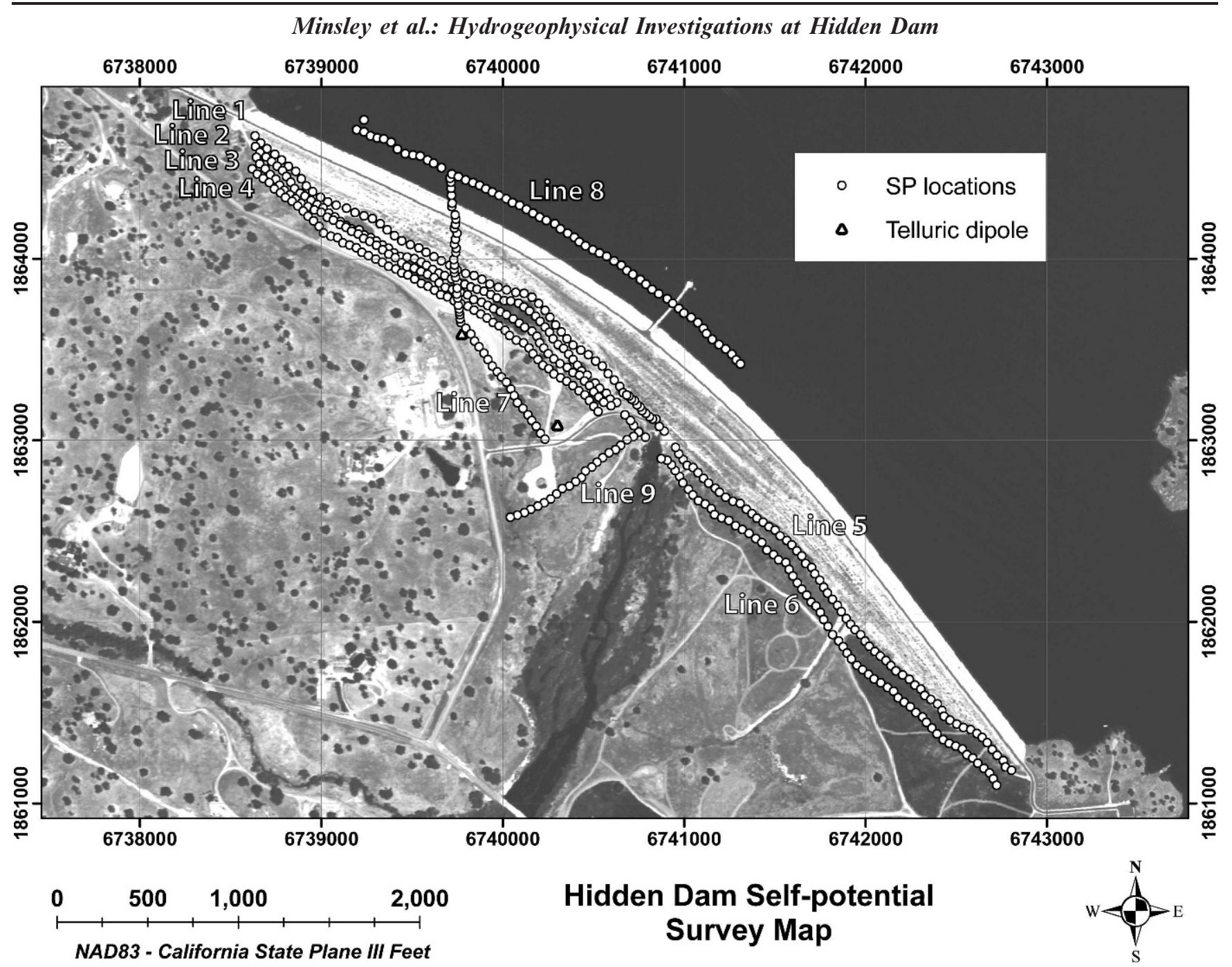

Figure 3. Self-potential survey stations (circles) and telluric dipole (triangles). Note that the reservoir elevation at the time of the aerial photo was higher than during the self-potential survey; actual electrode locations on the upstream side of the dam were immediately adjacent to the reservoir. Distances in meters equal 0.3048 times distances in feet.

es (typically less than $6 \mathrm{kohm}$ with bentonite and often greater than $15 \mathrm{kohm}$ without) as well as less scatter between measurements at a given station. The average standard deviation of the 15 measurements at each station was $1.7 \mathrm{mV}$, and 95 percent of the stations had a standard deviation less than $4.0 \mathrm{mV}$. This statistic is meant only to roughly describe the scatter in the measurements, and does not imply that the data errors follow a Gaussian distribution. In fact, self-potential measurements are prone to outliers (Corwin, 1990), and the processing strategies described below that are used to produce the final self-potential map account for this by incorporating a non-linear measure of data misfit that is appropriate for outliers and heavy-tailed distributions (Farquharson and Oldenburg, 1998; Minsley et al., 2008)

Additionally, a telluric monitoring dipole was installed to observe daily telluric variations that might corrupt the self-potential data. The single telluric dipole was installed in the same dam-parallel orientation as the vast majority of self-potential measurements, as this is the component of the telluric field that could affect the self-potential data. The telluric dipole (triangles, Fig. 3) consists of two non-polarizing electrodes installed in holes approximately $2 \mathrm{ft}(0.6 \mathrm{~m})$ deep and $720 \mathrm{ft}(219 \mathrm{~m})$ apart throughout the duration of the self-potential survey. An MT-24LF magnetotelluric recording system was used to record the telluric field at $6.25 \mathrm{~Hz}$ throughout each day of the self-potential survey. Telluric variations were typically less than $2 \mu \mathrm{V} \cdot \mathrm{ft}^{-1}$ $\left(6.5 \mu \mathrm{V} \cdot \mathrm{m}^{-1}\right)$, and were not considered to be a significant component of the total error in the data.

The raw self-potential data consist of measurements of the electrical potential between the base electrode and roving electrode for each line, as well as electrode drift measurements at the beginning and end 


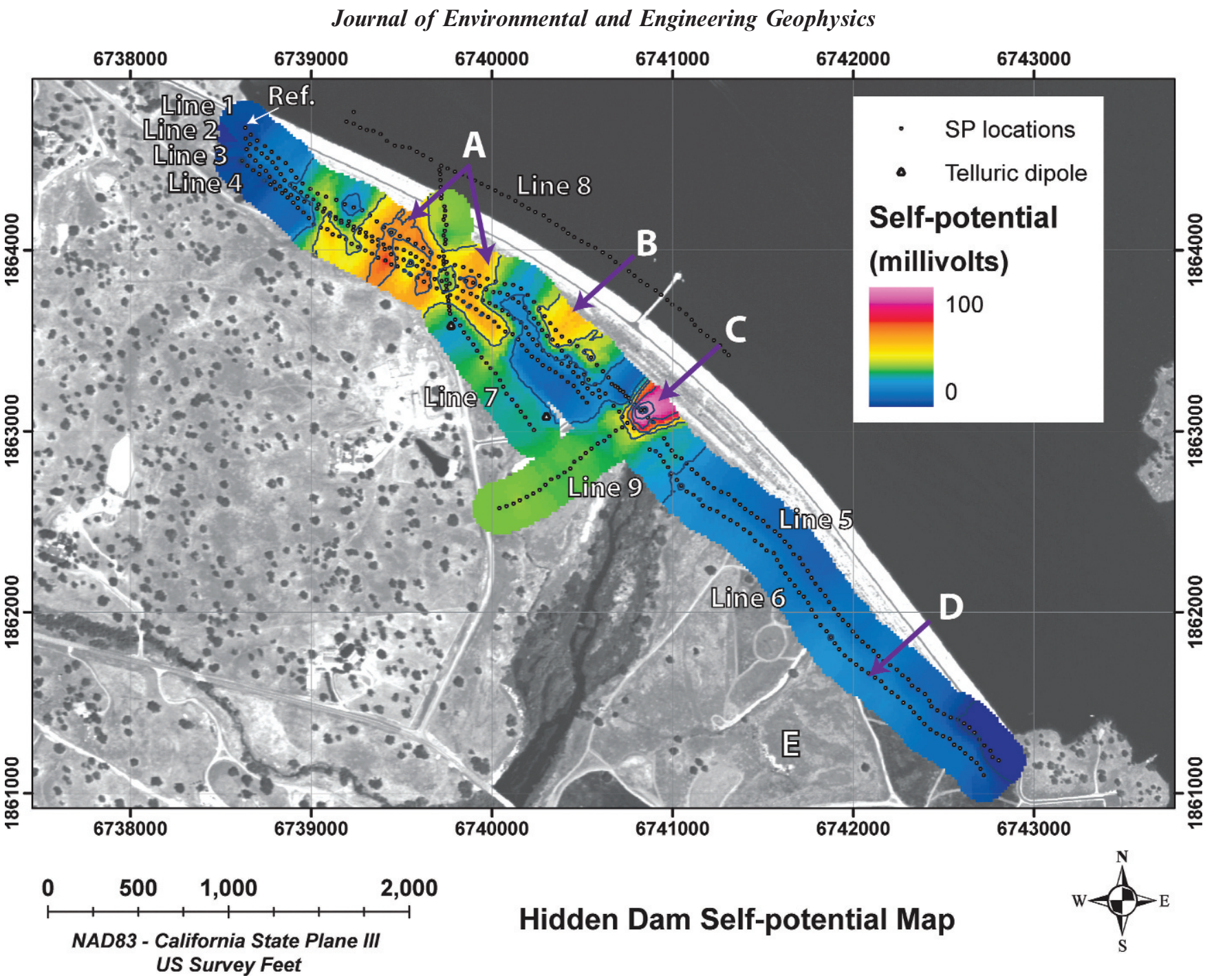

Figure 4. Interpolated self-potential map over the downstream portion of the survey area. The survey-wide reference electrode location is marked "Ref" in the northwest corner of the survey area. Locations A and B likely represent seepage areas over the drainage blanket. Location $\mathrm{C}$ may indicate an area of more focused shallow seepage in the area immediately around and above the fenced-in area surrounding the outlet works. Location D may represent relatively weak upwards seepage that does not intersect the ground surface, and is approximately $700 \mathrm{ft}$ upstream of a focused seepage area previously identified by Cedergren (1980a), which is marked as location E. Distances in meters equal 0.3048 times distances in feet.

of each line. These data are processed to produce a map of the electrical potential at every station relative to a survey-wide reference location, which is chosen as the northwestern-most point in the survey next to the downstream toe on the right abutment and is assigned a value of zero $\mathrm{mV}$. Measurements taken between the base stations of adjacent lines, as well as locations where two lines intersect, are critical in producing the final selfpotential map because these data provide information needed to tie all of the individual lines together. The final map was generated using the procedure discussed in more detail by Minsley et al. (2008), which produces a smoothly varying self-potential map that honors (1) measurements along each line, (2) errors estimated from the 15 measurements at each station, (3) electrode drift corrections, (4) a unique potential value at line intersection points, and (5) Kirchhoff's law, which requires that the total potential drop along any closed loop equals zero.

Figure 4 shows the resulting self-potential map (in $\mathrm{mV}$ ) relative to the survey-wide reference location in the northwest corner. An inverse-distance weighting function is used to generate the interpolated image from the inverted station potentials. The upstream data are omitted from this figure, and are displayed separately because of the questionable quality of their tie-in values 


\section{Minsley et al.: Hydrogeophysical Investigations at Hidden Dam}

relative to the downstream data. This is likely due to poor electrical contact on the riprap along the tie-line collected over the crest of the dam, as well as differences in oxidation-reduction (redox) and electrode diffusion for the measurements where the roving electrode was placed in the reservoir. Four likely seepage-related locations are marked on Fig. 4 based on the positive self-potential values in the vicinity of seepage outflow areas:

- Locations A and B: These areas of elevated selfpotential are very well correlated with the known seepage areas from the 1980 study (Cedergren, 1980a, 1980b), and therefore also with the location of the drainage blanket. The positive anomalies, on the order of $50-60 \mathrm{mV}$ in amplitude, seem to be focused in the areas of lower topography between several mounds on the downstream side of the dam. Lower self-potential values found on top of the mounds may be caused by (1) seepage being directed towards the relatively higher permeability drainage blanket and (2) increased distance from the ground surface to the seepage upflow, which can attenuate the self-potential signal.

- Location C: A large (+170 mV) and spatially focused (less than approximately $50 \mathrm{ft}(15 \mathrm{~m})$ wide) selfpotential anomaly is observed immediately around and above the fenced-in area surrounding the outlet works. The magnitude and peaked character of this anomaly suggest relatively focused and shallow outflow in this area. This, in addition to the fact that it is located somewhat uphill from the toe of the dam, supports the possibility that this could be related to piping or internal seepage exiting through the embankment rather than the foundation seepage associated with the locations A and B seepage areas. The proximity of this anomaly to the dam outlet structure leads to some concern that it may be a cultural-related artifact, which cannot be fully discounted. However, arguments for seepage include (1) noticeably wetter soil and greener vegetation in the vicinity of the anomaly and (2) the fact that metallic cultural sources are most often associated with negative self-potential anomalies.

- Location D: A very broad, low amplitude positive self-potential anomaly, approximately $20 \mathrm{mV}$ in magnitude, is observed in this location, which may be related to relatively weak upwards seepage that does not intersect the ground surface but continues mostly to the southwest along the local hydraulic gradient. A small area of focused seepage in a topographic low approximately $700 \mathrm{ft}(213 \mathrm{~m})$ downstream of location $\mathrm{D}$ was reported by Cedergren (1980a), and is marked as location E.
In general, the self-potential variability on the entire southeast (left) side of the dam is very weak compared with the northwest (right) side, thus corroborating the lack of observed seepage problems on the left side. We do, however, observe a gradual trend of increasing self-potentials from the "background" value measured on both the right and left abutments towards the dam centerline. This is illustrated in Fig. 5(A), which shows the self-potential profile along line 5 , which is closest to the downstream toe on the left side of the dam. This gradual increase towards a peaked value near the centerline is expected for normal under-flow conditions because there is a greater amount of flow under the center portion of the dam due to a larger hydraulic gradient than exists on the abutments where the downstream elevation is similar to that of the reservoir. The small (approximately $10 \mathrm{mV}$ ) positive excursions from this trend between 800 and 1,200 ft (244 and $366 \mathrm{~m}$ ) represent the potentially weak upwards seepage areas associated with location D in Fig. 4.

Figure 5(B) shows the self-potential profile collected in the reservoir immediately adjacent to the riprap on the upstream face of the dam on line 8 . The base electrode for this profile was located onshore next to the reservoir near the right abutment, and the roving electrode was placed in the water along the upstream face. As mentioned previously, there is some concern regarding the absolute value of self-potentials along this line relative to the downstream data because of the questionable quality of the tie line that crosses the dam crest, as well as possible influences from different redox conditions and diffusion related to having one electrode in the water and one onshore. Regardless of these issues, the self-potential trend in Fig. 5(B) is decreasing from the abutment towards the centerline, which is the opposite trend of the downstream line in Fig. 5(A) (increasing towards the centerline). This is the expected behavior on the upstream side of the dam, where greater head near the middle of the dam results in increased flow in the downstream direction, causing the selfpotentials in the upstream centerline area to be negative relative to the abutments.

\section{Direct Current (DC) Resistivity}

DC resistivity is an effective geophysical tool in dam-seepage studies because it is sensitive to changes in lithology, water saturation, and water chemistry (Binley and Kemna, 2005). Images of subsurface bulk electrical resistivity can therefore be used to help assess geologic units that may be more likely to conduct seepage through foundation or embankment materials, or to map regions of increased saturation. Numerous resistivity studies have focused on both internal erosion detection (Cho and Yeom, 2007; Kim et al., 2007; 
Journal of Environmental and Engineering Geophysics

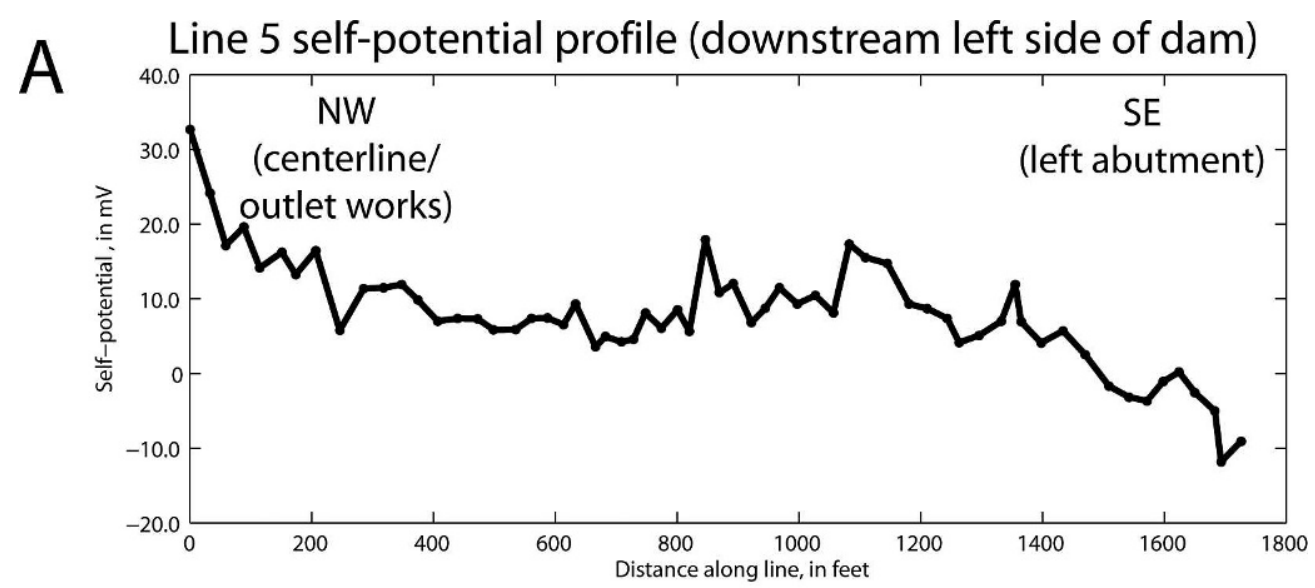

Line 8 self-potential profile (upstream right side of dam)

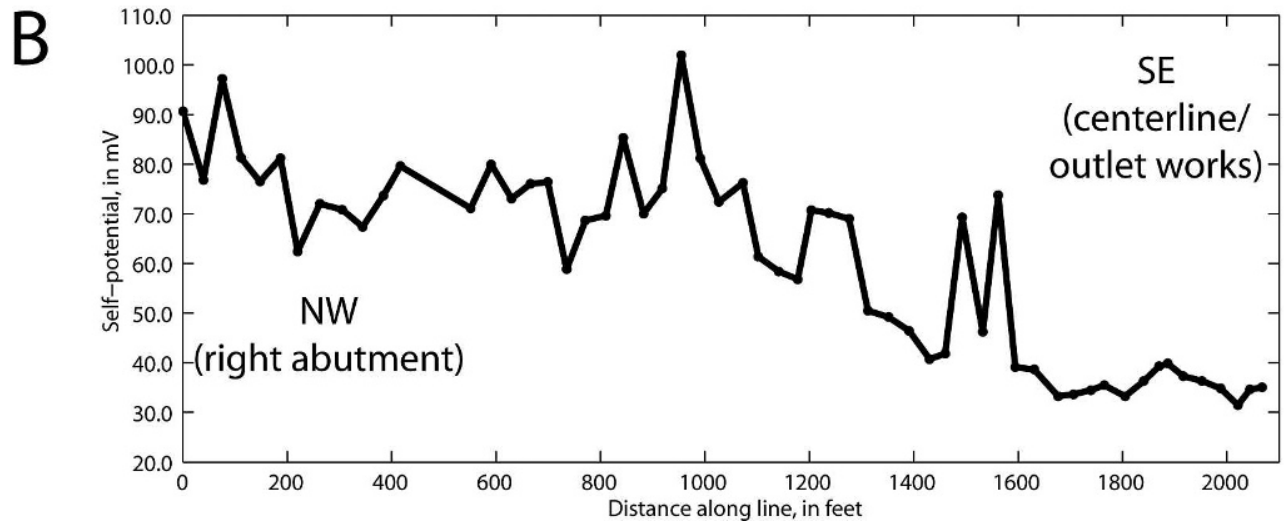

Figure 5. (A) Self-potential profile along the line closest to the downstream toe on the left side (line 5) of the dam illustrates a gradual increase towards the center of the dam expected during normal under-flow conditions. (B) Selfpotential profile along the line in the reservoir on the upstream side of the dam (line 8) illustrates a gradual decrease towards the center of the dam, also expected during normal under-flow conditions caused by increased head in the deeper center portion of the dam. Distances in meters equal 0.3048 times distances in feet.

Sjödahl et al., 2005, 2008) as well as identification of seepage pathways associated with dam foundation materials (Abu-Zeid, 1994; Di and Wang, 2010; Panthulu et al., 2001).

The focus of the present resistivity study is on imaging the subsurface beneath the downstream portion on the right side of Hidden Dam where seepage is known to have occurred. The survey objectives are (1) identifying potential seepage areas associated with changes in subsurface lithology and (2) determining depth to bedrock. Individual joints and fractures are particularly difficult targets to image, especially when their depths approach several tens of feet, because they are discrete features that involve a relatively small volumetric contrast in electrical properties. Zones of relatively high joint or fracture density, however, may result in a larger bulk contrast in electrical properties and are therefore more discernible geophysical targets.
Two two-dimensional (2-D) DC resistivity profiles were acquired along the western half of the downstream toe of the dam (Fig. 6). The data were acquired using a SuperSting R8 resistivity/IP meter by Advanced Geosciences, Inc. (AGI), which is an eight-channel multielectrode resistivity meter that uses a command file to acquire measurements from pre-determined current and potential electrode configurations. An "inverse Schlumberger" array geometry is utilized for this survey, which allows for rapid data acquisition and provides a good balance between lateral and depth resolution. The array consisted of 120 electrodes spaced at 10-ft (3-m) intervals along the line. For lines longer than the initial 120 electrode layout, continuous profiles were collected by moving a group of electrodes from the start of the line to the end, also known as the "roll-along" method. Multiple roll-alongs of 16 or 24 electrodes each were performed until the total desired line length was 


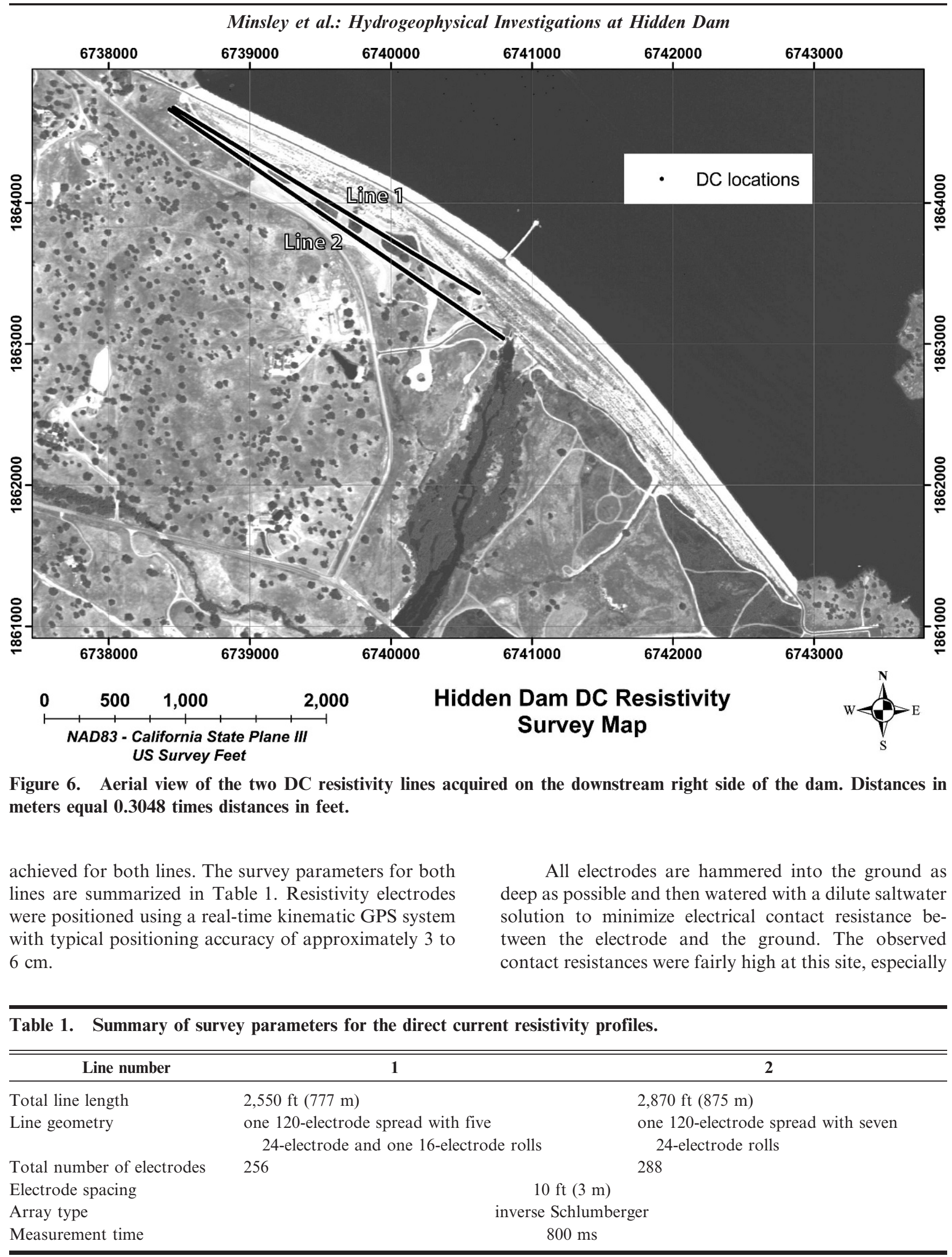


Journal of Environmental and Engineering Geophysics

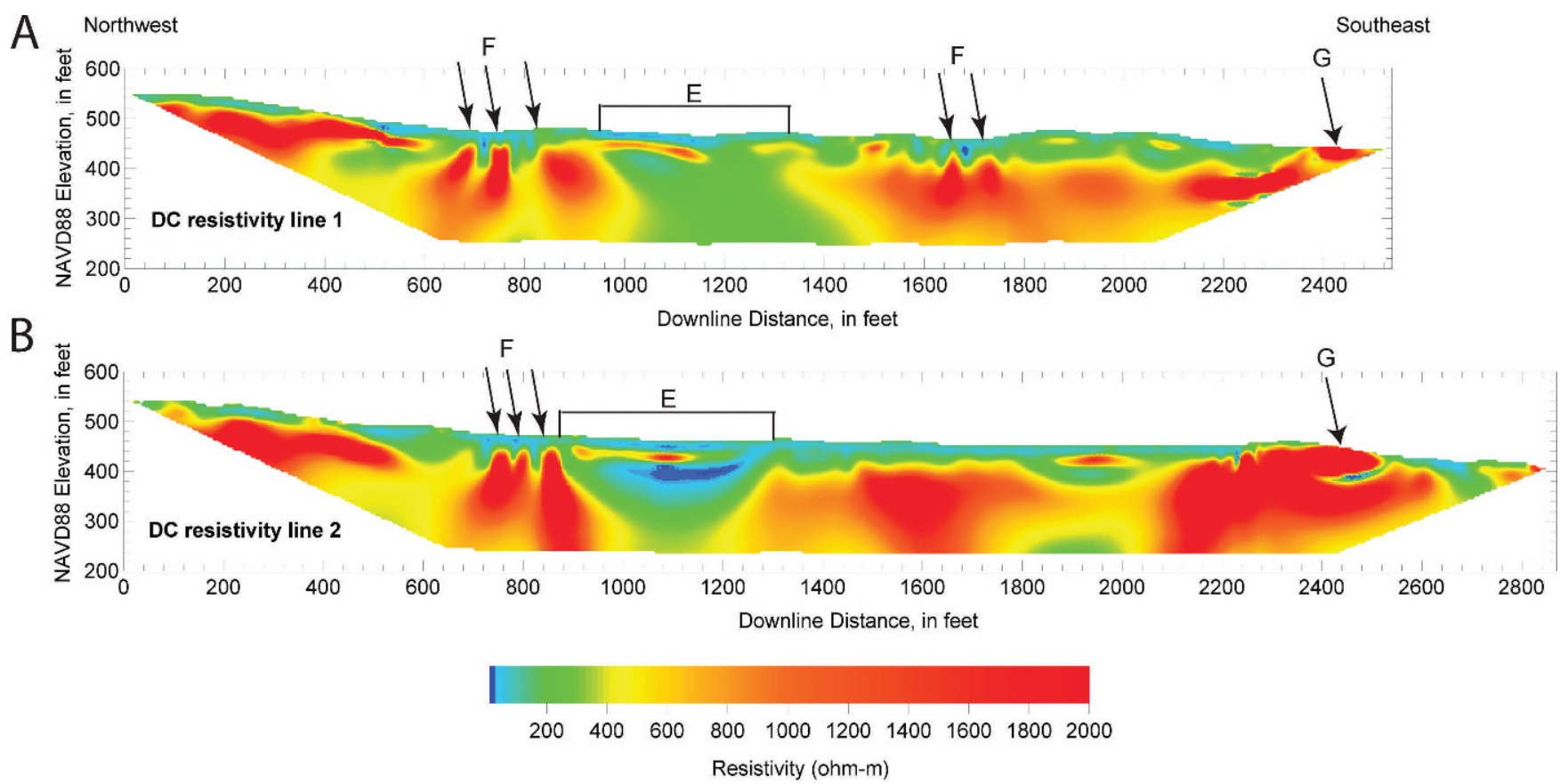

Figure 7. Inverted sections for DC resistivity (A) line 1 and (B) line 2. Location E, observed on both lines, is interpreted to be a deep alluvial valley between bedrock highs; locations $\mathrm{F}$ are highly resistive features that may represent competent granitic highs with complex geometry; and locations $G$ illustrate high near-surface resistivity associated with large granite outcrops. Distances and elevations in meters equal 0.3048 times values in feet.

over the gravel drainage blanket where there were relatively few fine-grained sediments. The contact resistances ranged from 2 to $9 \mathrm{kohm}$ along the gravel drainage blanket areas and were less than $2 \mathrm{kohm}$ in areas off of the blanket that had soil on the surface. A few short sections across the drainage blanket had contact resistances greater than $10 \mathrm{kohm}$, which required the addition of a bentonite mud to the base of the electrodes to further decrease the contact resistance (typically 4 to $7 \mathrm{kohm}$ after the addition of bentonite).

The resistivity data were inverted using AGI's EarthImager 2D software (AGI, 2008) using the "robust" inversion method, which is based on the assumption of an exponential distribution of data errors and performs well on noisy datasets. Topographic information was incorporated into the inversion in order to account for the influence of the irregular earth surface on the distribution of subsurface electrical currents, which is an important step towards determining a more accurate subsurface resistivity model. The inversions were initially run for 10 iterations, then the poorest-fit data points are removed using a percent data misfit threshold. The misfit threshold used for this survey is 30 percent and 40 percent, resulting in the removal of 6.6 percent and 5.9 percent of the total number of data points for lines 1 and 2, respectively.
The choice of a threshold value depends on the noise levels of the data and on the overall percentage of data that would be removed at those data misfit levels so as not to remove too large a percentage of the data. The inversion is then run a second time using the edited dataset to provide more reliable estimates of the resistivity structure.

Figure 7 shows the inverted sections for lines 1 and 2. On both lines, there is a moderately resistive (about 10 to $400 \mathrm{ohm}-\mathrm{m}$; blue to yellow colors) upper layer that varies in thickness from 0 to approximately $80 \mathrm{ft}(24 \mathrm{~m})$ overlying a strongly resistive (greater than $800 \mathrm{ohm}-\mathrm{m}$; orange to red colors) layer. Based on the known geology of the area, the upper layer is interpreted to be a combination of alluvial overburden and decomposed, or weathered, granitic bedrock. Without additional borehole or lithologic information to compare directly with the data, it is difficult to conclusively determine the overburden/decomposed bedrock contact. Under saturated conditions, both of these units can have similar electrical properties. The deeper resistor is interpreted as less weathered granitic bedrock, where the more highly weathered/jointed sections are interpreted to have a lower resistivity than the more competent bedrock. These weathered sections in the competent bedrock represent potential groundwater pathways. Several other notable features annotated in Fig. 7 are described below: 


\section{Minsley et al.: Hydrogeophysical Investigations at Hidden Dam}

- Location E: The most notable feature that is present in both lines is a less resistive zone with a maximum width of about $400 \mathrm{ft}(122 \mathrm{~m})$ interpreted as an alluvial valley between bedrock highs. Based on the trend between lines 1 and 2, the valley appears to trend northeast-southwest and becomes shallower and narrower on line 2. The shallow dark blue zones on line 2 possibly indicate saturated areas of greater porosity or increased concentrations of clay. The source of the thin, shallow discontinuous resistor about $30 \mathrm{ft}(9 \mathrm{~m})$ below the surface on both lines is unknown. Although it is possible that it represents a low porosity/permeability layer, this requires further analysis to determine the robustness and structure of this feature in the model. A similar thin resistor is located between 1,880 and 2,000 ft (573 and $610 \mathrm{~m}$ ) downline distance on line 2.

- Locations F: There are several highly resistive vertical features that begin about $30 \mathrm{ft}(9 \mathrm{~m})$ below the surface. They tend to have a character indicative of three-dimensional objects either along line or offline improperly imaged with a two-dimensional profile. These objects may represent competent granitic highs, but their true three-dimensional geometry may not be well-resolved.

- Locations G: The high near-surface resistivity observed towards the southeastern end of both lines corresponds with several large granite outcrops observed in the field. Somewhat surprisingly, there are only a few areas where the strong resistor reaches the surface, despite the numerous outcrops observed along both lines. The numerous topographically high areas were originally thought to be more resistive outcrops below the surface. The inversions, however, indicate that most of these areas are of only moderate resistivity, and although they may still be granitic, are most likely decomposed and potentially have clay-filled joints and fractures.

The large, low-resistivity valley observed at locations $\mathrm{E}$ in Fig. 7 indicates a likely pathway for increased groundwater seepage flow underneath the dam. This conclusion is supported by the fact that this location also corresponds very well with the selfpotential anomaly at location $\mathrm{A}$ in Fig. 4 that indicates upward seepage flow in this location. In general, it is likely that the geometry of the more competent (more resistive) bedrock is a strong controlling factor for subsurface flow paths. Regions of thicker alluvium and (or) weathered granite will be preferential pathways for flow. This subsurface structural geometry, in conjunction with the surface topography, is likely the largest factor contributing to the observed seepage at Hidden Dam.

\section{Hydrogeophysical Simulations}

Two-dimensional flow simulations that are representative of likely hydrogeologic scenarios at Hidden Dam are carried out to supplement information about seepage provided by the geophysical surveys reported here and historical piezometer and observation well data. Hydrogeologic models for the flow simulations are based on information from the dam foundation report and known hydrogeology of the site (Cedergren, 1980a, 1980b; U.S. Army Corps of Engineers, 1977), and are also guided by the geophysical results discussed above. The finite element modeling package, COMSOL Multiphysics, is utilized to solve the steady-state Richards equation for variably saturated flow (Freeze and Cherry, 1979), where the van Genuchten (van Genuchten, 1980) parameterization is used to describe the saturation-dependent hydraulic properties, as described in the Appendix.

Additionally, bulk electrical resistivity is predicted for the various flow scenarios by incorporating the dynamically calculated saturation into Archie's law (Archie, 1942), and the self-potential response is predicted by coupling the flow equations to the governing equations for electrokinetic flow within COMSOL, which is also described in the Appendix. Dynamically coupling flow simulations with geophysical responses can be a powerful survey design tool to test the sensitivity of various geophysical measurements to the expected subsurface behavior (Minsley et al., 2010), and can also be used to evaluate the validity of the assumed hydrogeologic model by comparing measured data with predicted responses.

Figure 8 shows the basic model geometry used for the flow simulations, where the geometry and hydraulic properties of the various embankment units are derived from the foundation report (U.S. Army Corps of Engineers, 1977) as discussed in the Appendix. The topography of the downstream surface is extracted from a digital elevation model at the Hidden Dam site along two different profiles (Fig. 1), and helps to provide a realistic representation of topographic controls on seepage. The relevant hydraulic properties for the various units in Fig. 8 are summarized in Table 2.

For each of the five different modeling scenarios outlined in Table 3, flow simulations are run for reservoir elevations between $480 \mathrm{ft}(146 \mathrm{~m})$ and $540 \mathrm{ft}$ $(165 \mathrm{~m})$. These flow scenarios are meant to be representative of changes in internal structure and foundation properties that are found along the length of the dam. At each reservoir elevation, predictions can be made for flow throughout the model, saturation, seepage at the ground surface, subsurface pressure, bulk electrical resistivity, or self-potential. Comparing the 
Journal of Environmental and Engineering Geophysics

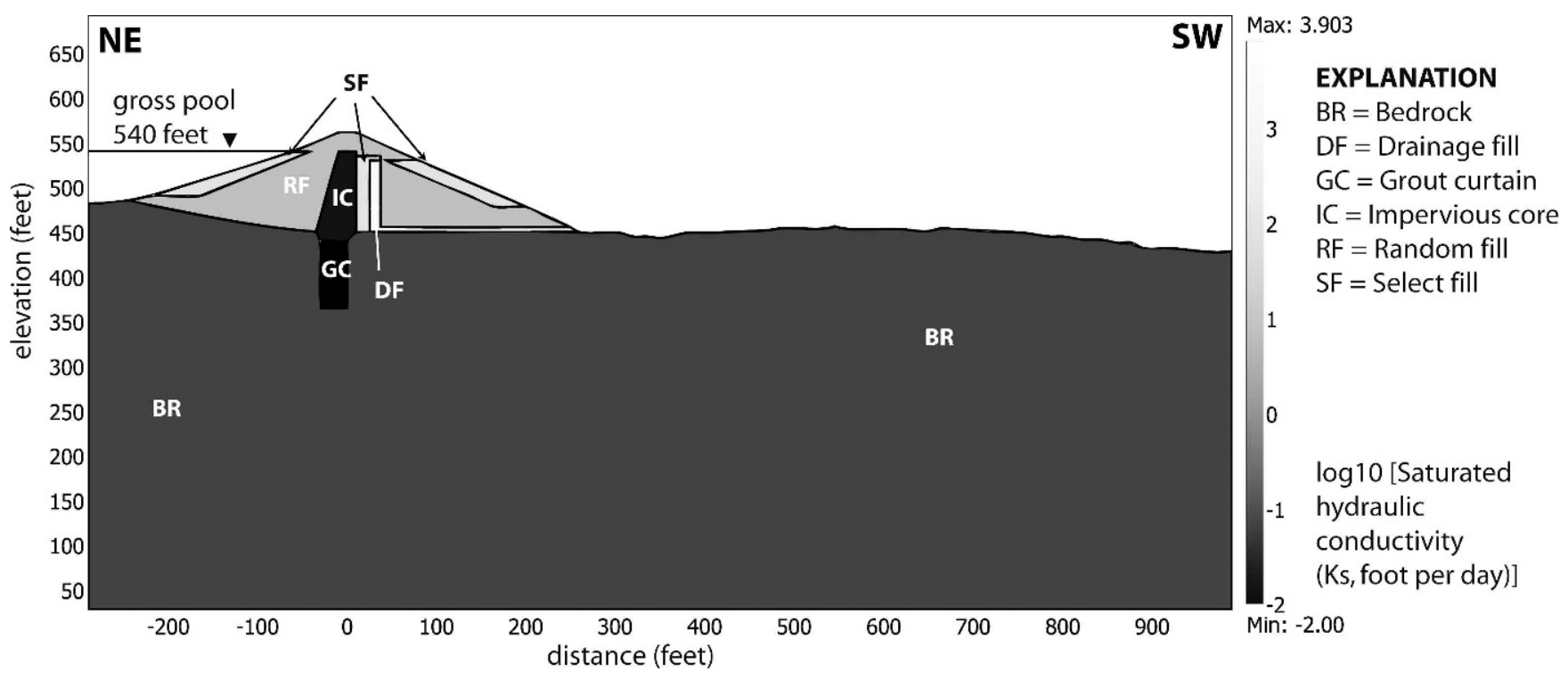

Figure 8. Model geometry and domains used for the scenario 1 flow model. Distances in meters equal 0.3048 times distances in feet. Hydraulic conductivity in meters per day equals 0.3048 times hydraulic conductivity in feet per day.

predictions with piezometer and observation well data, along with the results of the geophysical surveys, provides useful insight into the likely conditions at the dam.

Figure 9 shows the flow modeling results for flow scenario 1 at simulated reservoir elevations $485 \mathrm{ft}$ $(148 \mathrm{~m})(\mathrm{A}), 510 \mathrm{ft}(155 \mathrm{~m})(\mathrm{B})$, and $540 \mathrm{ft}(165 \mathrm{~m})$ (C). There is a clear increase in seepage through the upstream portion of the embankment and foundation, as indicated by the flow arrows. Increased saturation in the upstream embankment, as well as some of the downstream high-topography areas, is also observed with increasing reservoir elevation. The efficacy of the downstream horizontal drainage fill (DF) is evident in this scenario compared with scenario 3 (not shown), as it redirects potentially erosive upwards seepage away from the embankment and out the toe of the dam. Additionally, these modeling results illustrate the focusing effect that the downstream low-topography areas have on seepage patterns. This is consistent with the previous observations of seepage at Hidden Dam (Cedergren, 1980a) and the need for the downstream drainage blanket.

Figure 10 illustrates examples of several of the quantitative predictions that can be made from the coupled flow simulations. In Fig. 10(A), outward flux through the surface of the downstream portion of the dam and along the downstream topography is displayed for the three different reservoir elevations shown in Fig. 9. The sharp, large outward flux observed at approximately $275 \mathrm{ft}(84 \mathrm{~m})$ coincides with the outlet of the high-hydraulic conductivity drainage fill (DF) that drains the embankment material. The other spikes in outward flux between $280-400 \mathrm{ft}(85-122 \mathrm{~m})$ and 900 $1,000 \mathrm{ft}$ (274-305 $\mathrm{m}$ ) are caused by seepage being focused in the low-topography areas downstream of the dam.

Figure 10(B) shows the predicted self-potential response for the same profile and reservoir elevations as

Table 2. Baseline parameters for each Hidden Dam unit used in the variably saturated flow model.

\begin{tabular}{|c|c|c|c|c|c|c|c|}
\hline & $\begin{array}{c}\text { Saturated hydraulic } \\
\text { conductivity, } \mathrm{K}_{\mathrm{s}} \\
(\mathrm{m} / \mathrm{day})\end{array}$ & $\begin{array}{c}\text { Saturated } \\
\text { moisture content, } \theta_{\mathrm{s}} \\
\text { (volume fraction) }\end{array}$ & $\begin{array}{l}\text { Residual moisture } \\
\text { content, } \theta_{\mathbf{r}} \\
\text { (volume fraction) }\end{array}$ & a $(1 / m)$ & $\mathbf{n}$ & $\begin{array}{c}\text { Water } \\
\text { density, } \\
\rho\left(\mathrm{kg} / \mathrm{m}^{3}\right)\end{array}$ & $\begin{array}{c}\text { Fluid } \\
\text { source, } \\
Q_{\text {s }}(1 / s)\end{array}$ \\
\hline Bedrock (BR) & 0.030 & 0.150 & 0.050 & 0.6561 & 2.000 & \multirow{6}{*}{1,000} & \multirow{6}{*}{0} \\
\hline Impervious core (IC) & 0.0061 & 0.418 & 0.210 & 0.6604 & 1.9923 & & \\
\hline Random fill (RF) & 0.30 & 0.372 & 0.015 & 0.7871 & 3.9218 & & \\
\hline Select fill (SF) & 0.61 & 0.375 & 0.014 & 0.8048 & 3.3088 & & \\
\hline Drainage fill (DF) & 2,438 & 0.425 & 0.020 & 2.351 & 3.5952 & & \\
\hline Grout curtain (GC) & 0.0030 & 0.05 & 0.005 & 0.6561 & 2.0000 & & \\
\hline
\end{tabular}


Table 3. Summary of models investigated through flow simulations.

\begin{tabular}{cl}
\hline \hline Flow scenario & Description \\
\hline 1 & "Baseline" model shown in Fig. 8 uses topography extracted along southeastern profile (Fig. 1) \\
2 & Same units as scenario \#1, but using topography extracted along northwestern profile (Fig. 1) \\
3 & Same as scenario \#1, but no high hydraulic conductivity horizontal drainage fill (DF) \\
4 & Same as scenario \#1, but with a thin $(20-30 \mathrm{ft})$ sediment layer over bedrock on the downstream side of the dam \\
5 & Same as scenario \#1, but with a thick (300 ft) sediment channel over bedrock connecting the upstream and \\
& downstream portions of the model
\end{tabular}

in Fig. 10(A) based on the electrokinetic coupling procedure described in the Appendix. There is a positive shift in the self-potential signal as the reservoir elevation increases, which can be expected because of the increased seepage under the dam with increasing reservoir elevation. Positive excursions from the general trend are also observed in the seepage areas highlighted in Fig. 10(A), which is also consistent with increased upwards flow in the low topography areas as well as the observed self-potential data at Hidden Dam (Fig. 4, locations $\mathrm{A}$ and $\mathrm{B}$ ). Another interesting feature in Fig. 10(B) is the self-potential low that develops around $0-150 \mathrm{ft}(46 \mathrm{~m})$ for the $540 \mathrm{ft}(165 \mathrm{~m})$ reservoir elevation, which is likely caused by the increased downwards component of flow that is shown in Fig. 9(C).

Because the self-potential response is a function of the electrical resistivity structure and electrokinetic coupling coefficient, inaccuracies in our assumptions about these properties may lead to some change in the predicted self-potential response, though the overall shape of the response is likely representative. As described in the Appendix, the electrical resistivity and coupling coefficient are functions of the estimated porosity and hydraulic permeability (Table 2), which may be inaccurate. Additionally, there can be uncertainty in the empirical relationships used to calculate the resistivity and coupling coefficient. For example, the relationship for the coupling coefficient provided in Eq. (A-8) in the Appendix was derived from the best fit to a diverse set of geologic materials. Modest changes $(5 \%)$ in the slope and intercept of this relationship can lead to significant ( 1 to 2 orders of magnitude) changes in the predicted coupling coefficient because of the logarithmic nature of the relationship. Therefore, the estimates in Fig. 10(B) should be regarded as a semi-quantitative estimate of the self-potential response. The overall shape of the curves are likely representative, but the amplitudes may need to be scaled significantly because of the potential variability in the coupling coefficient. Estimation of a site-specific coupling coefficient by laboratory analysis of samples taken from the Hidden Dam site would be an effective way to reduce this uncertainty for future investigations.

Finally, in Fig. 11, we compare the historical record of water levels observed in observation well OW-7 with predictions from flow scenario 2 (Table 3 ). OW-7 is chosen for this comparison because it is located in the downstream seepage area (Fig. 1) and has a similar top elevation as the scenario 2 model $(470 \mathrm{ft}$ $(143 \mathrm{~m})$ ). Additionally, effective water levels above ground surface were obtained in OW-7 by using pressure transducers. The historical record includes monthly observations since 1980. There is a good correspondence between the historical data and flow simulation predictions, though the water levels are overpredicted by several feet at lower reservoir elevations, possibly because of complexities not captured in the scenarios studied here. Further modeling efforts are needed to test potential hydrogeologic factors that could result in a better match between observed and predicted water levels.

Flow scenario 4, which includes a thin (tens of $\mathrm{ft}$ ) sedimentary layer with higher hydraulic conductivity than the underlying bedrock, results in moderately increased seepage in the downstream area (not shown). A greater proportion of the seepage is through the sediment and bedrock rather than the embankment because of the net increase in hydraulic conductivity in the foundation materials. The presence of a deep (hundreds of $\mathrm{ft}$ ) sedimentary channel under the dam foundation (scenario 5) suggested by the resistivity survey leads to substantial increases in volumetric seepage under the dam (not shown), though water levels predicted in observation wells are comparable to the case without a high-conductivity channel. This observation of increased seepage, but unchanged water levels (pressure), is predicted from normal Darcy flow (Freeze and Cherry, 1979): the increased hydraulic conductivity in the sediment channel leads to increased flow, but the pressure gradient (defined by the ratio of flow to hydraulic conductivity) remains unchanged. This suggests that water level data alone may not be a good 
Journal of Environmental and Engineering Geophysics

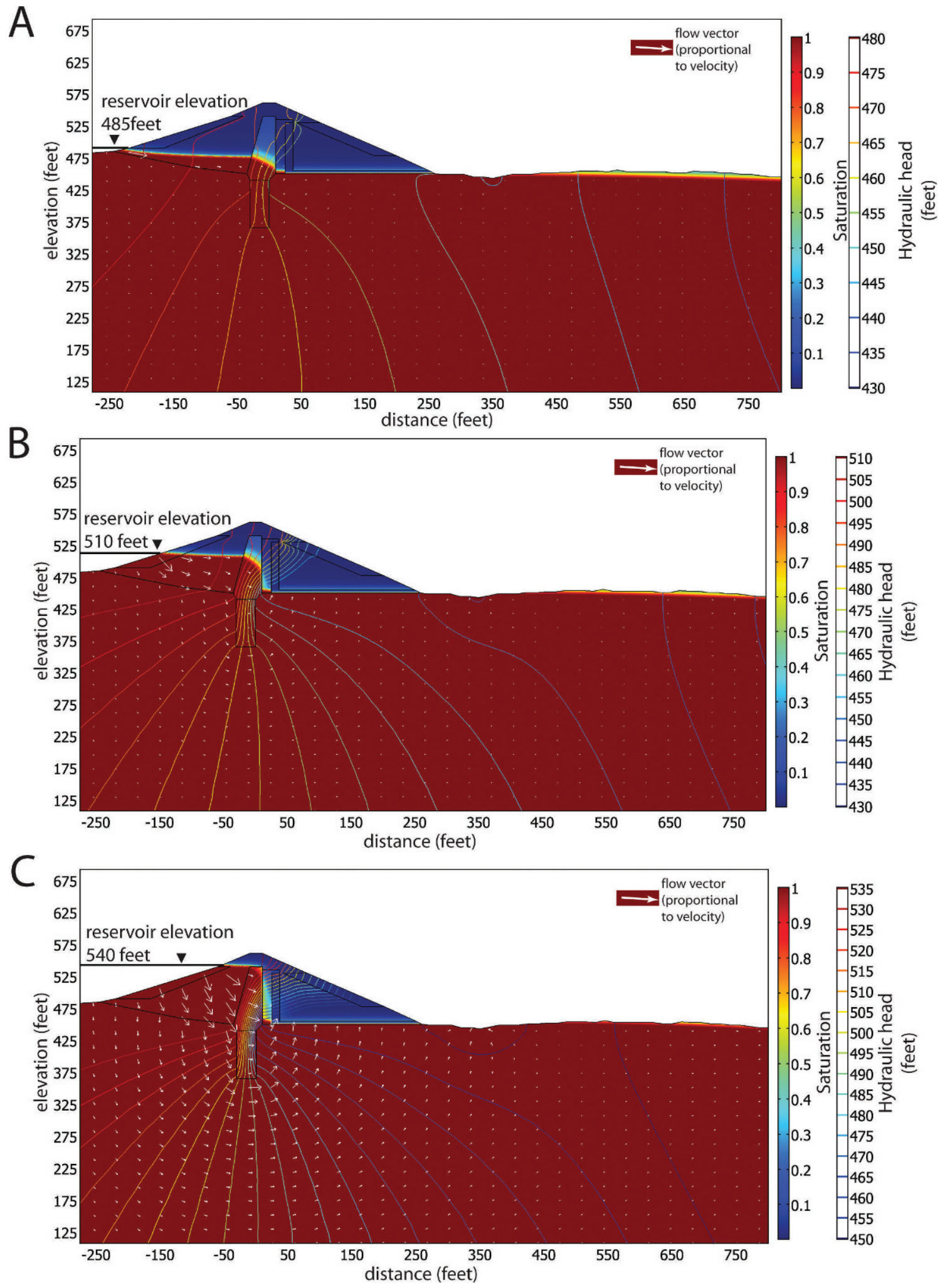

Figure 9. Flow simulations for the scenario 1 model at reservoir elevations $485 \mathrm{ft}(\mathrm{A}), \mathbf{5 1 0} \mathrm{ft}(\mathrm{B})$, and $540 \mathrm{ft}(\mathrm{C})$. Rising reservoir elevations result in progressively increased saturation in the upstream portion of the embankment and flow through the model. The high-hydraulic conductivity horizontal drainage fill (df) is effective in rapidly draining flow to the toe of the dam and maintains unsaturated conditions in the downstream portion of the embankment. Distances, elevations, and heads in meters equal 0.3048 times values in feet. 

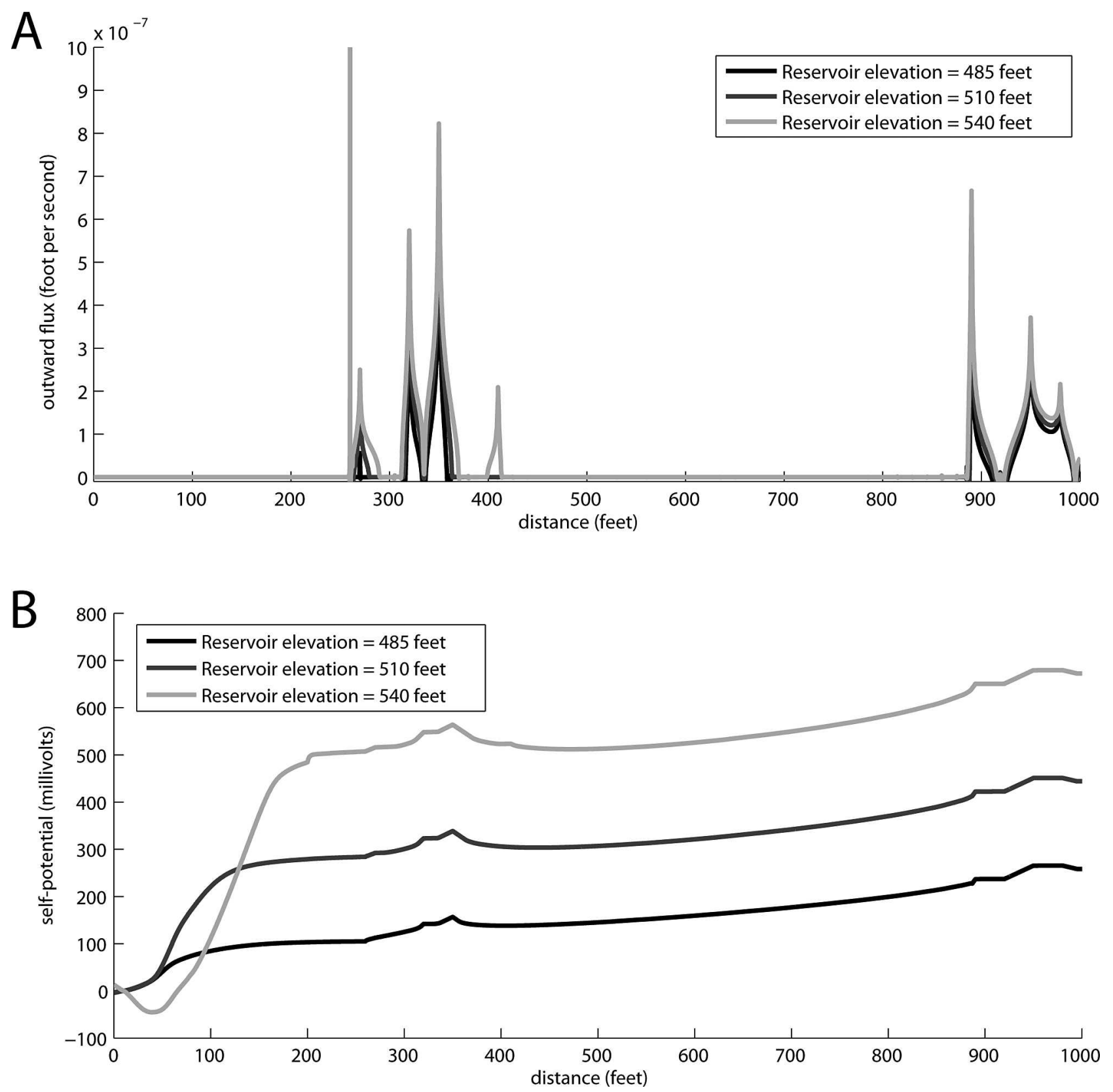

Figure 10. Outward seepage (A) and self-potentials (B) predicted as a function of distance along the downstream embankment and ground surface for the three different reservoir elevations shown in Fig. 9. Distances and elevations in meters equal 0.3048 times values in feet. Flux in meters per second equal 0.3048 times flux in feet per second.

indicator of relative amounts of seepage along the dam if the wells are located in different geologic structures.

While the two-dimensional flow scenarios provide useful information about the character of flow through the dam and the relative influence of different dam and foundation materials, there is likely a three-dimensional component to flow at the Hidden Dam site caused by topographic variations along the strike of the dam as well as the topography of the bedrock surface. To first order, this would involve a component of flow towards the low elevation areas along the centerline of the dam, but local effects caused by the rolling surface and bedrock topography may also be relevant in controlling flow. Three-dimensional modeling was not possible in this study because of the large number of parameters required to model flow, especially when incorporating small-scale features such as the drainage fill. Future work could benefit from simulating three-dimensional 
Journal of Environmental and Engineering Geophysics

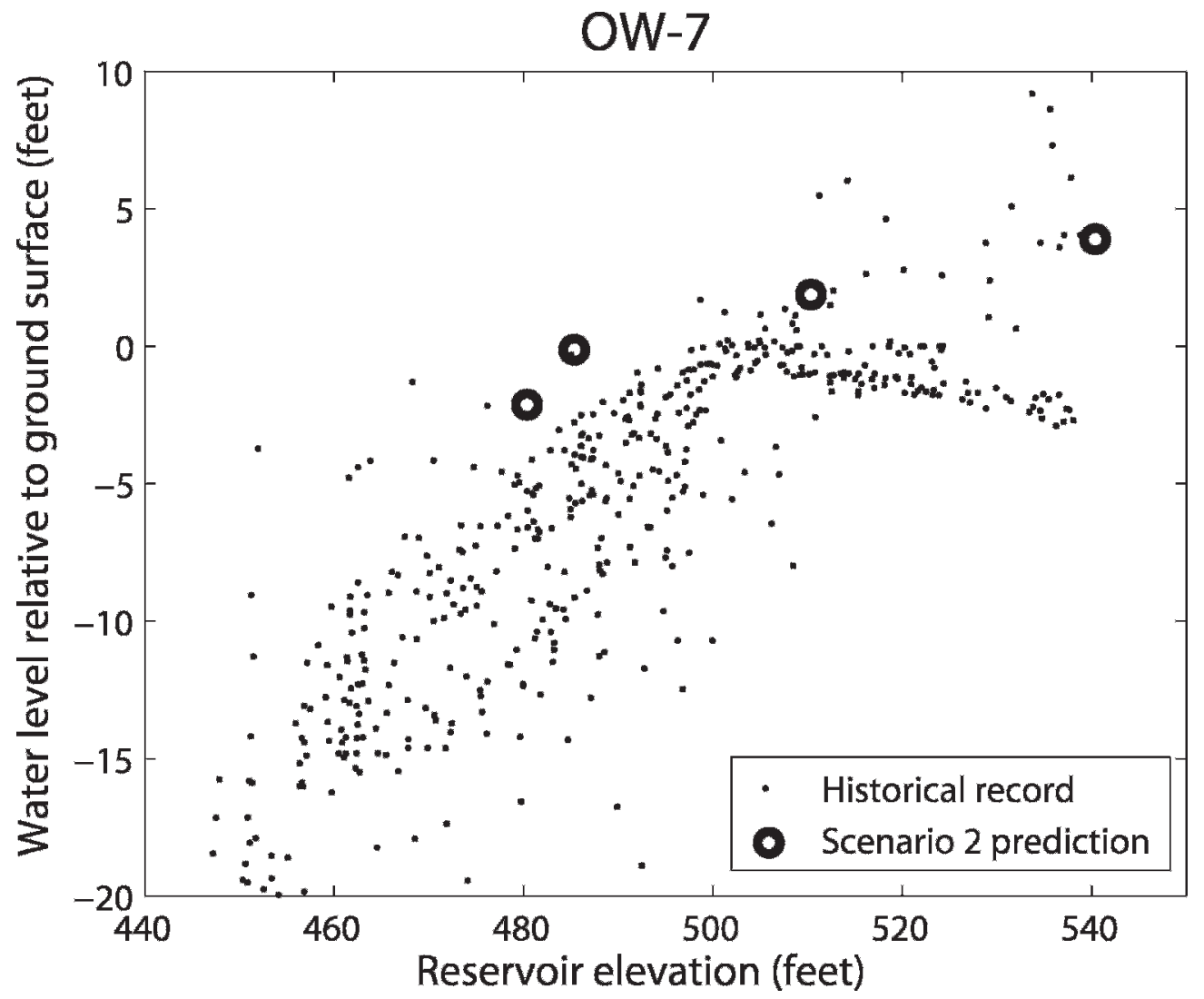

Figure 11. Comparison of the historical trend of observed water levels in observation well OW-7 (solid dots) with those predicted by flow scenario 2 (open circles) as a function of reservoir elevation. Elevations in meters equal 0.3048 times elevations in feet.

flow to better predict seepage areas at the site, but will likely require a more generic dam model that does not include all of the structural detail explored in this study.

\section{Conclusions}

Self-potential and electrical resistivity surveys at Hidden Dam have provided valuable information regarding the hydrogeologic factors contributing to seepage observed at the site. The self-potential data confirm known seepage areas in the vicinity of the drainage blanket on the northwest (right) side of the dam, little-to-no seepage on the southeast (left) side of the dam, and a potentially focused area of seepage immediately above the outlet works. The resistivity cross-sections provide a useful means for delineating subsurface structural variability that controls flow patterns. Enhanced flow is most likely to occur in the regions that contain sediments or weathered granite, and therefore increased porosity and permeability, rather than areas of more competent bedrock. Most prominently, the resistivity models indicate a fairly wide sediment channel that is likely a contributing factor to the known seepage area on the right side of the dam. The upstream reservoir head, geometry of the competent granite in the subsurface, and downstream surface topography are likely the most significant controlling factors for the observed seepage.

Numerical modeling of likely flow scenarios and the predicted geophysical response provides valuable additional information about possible seepage behavior at the Hidden Dam site. This also provides a framework for iteratively updating hydrogeologic assumptions by comparing predicted responses with hydraulic and geophysical measurements. Modeling results can also be used to help guide future geophysical work or site new monitoring wells. This work focused primarily on understanding seepage patterns through the dam foundation, but future studies could easily incorporate seepage mechanisms through the embankment as well. Including variability in downstream topography in the dam-parallel direction would also provide more accurate flow simulations and a better indication of the importance of three-dimensional flow pathways at the site.

While the primary focus of this work is on the analysis of present-day seepage conditions at the Hidden 


\section{Minsley et al.: Hydrogeophysical Investigations at Hidden Dam}

Dam site, we hope to further develop the use of coupled hydrogeophysical modeling and inversion. A fully integrated approach would involve the use of both hydraulic and geophysical measurements used together to directly inform hydrogeologic models and better understand dynamic seepage patterns.

\section{Acknowledgments}

This work was carried out with the support of the U.S. Army Corps of Engineers, Sacramento District, under the supervision of Lewis Hunter. We are grateful for field assistance provided by Jonah Sullivan and Katie Jeffcoat. Significant logistical support and on-site information was provided by the Hidden Dam staff, particularly Phil Smith and Dale Dawson. We thank André Revil, Kevin Hazleton, Andrey Kazak, Victor Kalinin, and John Deceuster for their reviews of this manuscript. A portion of author S. Ikard's time was covered by the NSF-funded SmartGeo Educational Program (Project IGERT: Intelligent Geosystems; DGE0801692).

\section{References}

Abu-Zeid, N., 1994, Investigation of channel seepage areas at the existing Kaffrein Dam Site (Jordan) using electrical resistivity measurements: Journal of Applied Geophysics, 32, 163-175.

AGI, 2008, Instruction manual for EarthImager2D version 2.3.0 - resistivity and IP inversion software, Advanced Geosciences, Inc., Austin, Texas.

Archie, G.E., 1942, The electrical resistivity log as an aid in determining some reservoir characteristics: Trans. Amer. Inst. Mining Metallurgical and Petroleum Engineers, 146, 54-62.

Bateman, P.C., Clark, L.D., Huber, N.K., Moore, J.G., and Rinehart, C.D., 1963, The Sierra Nevada batholith- A synthesis of recent work across the central part: U.S. Geological Survey Professional Paper 414-D.

Bauer-Gottwein, P., Gondwe, B.N., Christiansen, L., Herckenrath, D., Kgothang, L., and Zimmerman, S., 2010, Hydrogeophysical exploration of three-dimensional salinity anomalies with the time-domain electromagnetic method (TDEM): Journal of Hydrology, 380, 318-329.

Berube, A.P., 2007, A graphical 3D finite element program for modelling self-potentials generated by flow through a porous medium: Journal of Environmental and Engineering Geophysics, 12, 185-197.

Binley, A., and Kemna, A., 2005, DC resistivity and induced polarization methods: in Hydrogeophysics, Rubin, Y., and Hubbard, S.S. (eds.), Springer, Netherlands, 129-156.

Bogoslovsky, V., and Ogilvy, A., 1970a, Application of geophysical methods for studying the technical status of earth dams: Geophysical Prospecting, 18, 758-773.

Bogoslovsky, V.A., and Ogilvy, A.A., 1970b, Natural potential anomalies as a quantitative index of the rate of seepage from water reservoirs: Geophysical Prospecting, 18, 261-268.

Bolève, A., Revil, A., Janod, F., Mattiuzzo, J.L., and Fry, J.J., 2009, Preferential fluid flow pathways in embankment dams imaged by self-potential tomography: Near Surface Geophysics, 7, 447-462.

Cedergren, H.R., 1980a, Seepage study of Hidden Dam, Fresno River, California: Prepared for Department of the Army, Sacramento District, Corps of Engineers.

Cedergren, H.R., 1980b, Seepage study of Hidden Dam, Fresno River, California: Analysis of data from observation wells put in right abutment seepage areas in 1980: Prepared for Department of the Army, Sacramento District, Corps of Engineers.

Cho, I.-K., and Yeom, J.-Y., 2007, Crossline resistivity tomography for the delineation of anomalous seepage pathways in an embankment dam: Geophysics, 72, G31-G38.

Chui, T.F.M., and Freyberg, D.L., 2009, Implementing hydrologic boundary conditions in a multiphysics model: Journal of Hydrologic Engineering, 14, 1374 1377.

Corwin, R.F., 1990, The self-potential method for environmental and engineering applications: in Geotechnical and Environmental Geophysics, Ward, S.H. (ed.), Society of Exploration Geophysicists, Tulsa, 127-146.

Corwin, R.F., 2007. Investigation of geophysical methods for assessing seepage and internal erosion in embankment dams: Interpretation of self-potential data for dam seepage investigations, Report T992700-0205B/3, Canadian Electricity Association Technologies Inc. (CEATI), Montreal.

Dahlin, T., Sjödahl, P., and Johansson, S., 2008. Investigation of geophysical methods for assessing seepage and internal erosion in embankment dams: A guide to resistivity investigation and monitoring of embankment dams, Canadian Electricity Association Technologies Inc. (CEATI), Montreal.

Di, Q., and Wang, M., 2010, Determining areas of leakage in the Da Ye Dam using multi-electrode resistivity: Bulletin of Engineering Geology and the Environment, 69, 105-109.

Farquharson, C.G., and Oldenburg, D.W., 1998, Non-linear inversion using general measures of data misfit and model structure: Geophysical Journal International, 134, 213-227.

Ferré, T., Bentley, L., Binley, A., Linde, N., Kemna, A., Singha, K., Holliger, K., Huisman, J.A., and Minsley, B., 2009, Critical steps for the continuing advancement of hydrogeophysics: Eos, 90, 200.

Freeze, R.A., and Cherry, J.A., 1979. Groundwater, Prentice Hall, Englewood Cliffs, New Jersey, 604.

Hinnell, A.C., Ferre, T.P.A., Vrugt, J.A., Huisman, J.A., Moysey, S., Rings, J., and Kowalsky, M.B., 2010, Improved extraction of hydrologic information from geophysical data through coupled hydrogeophysical inversion: Water Resources Research, 46.

Ishido, T., and Mizutani, H., 1981, Experimental and theoretical basis of electrokinetic phenomena in rock- 


\section{Journal of Environmental and Engineering Geophysics}

water systems and its applications to geophysics: Journal of Geophysical Research, 86, 1763-1775.

Jardani, A., Revil, A., Boleve, A., and Dupont, J.P., 2008, Three-dimensional inversion of self-potential data used to constrain the pattern of groundwater flow in geothermal fields: Journal of Geophysical ResearchSolid Earth, 113, B09204.

Kim, J.-H., Yi, M.-J., Song, Y., Seol, S.J., and Kim, K.-S., 2007, Application of geophysical methods to the safety analysis of an earth dam: Journal of Environmental and Engineering Geophysics, 12, 221-235.

Lesmes, D.P., and Friedman, S.P., 2005, Relationships between the electrical and hydrogeological properties of rocks and soils: in Hydrogeophysics, Rubin, Y., and Hubbard, S.S. (eds.), Springer, Netherlands, 87-128.

Minsley, B.J., Ajo-Franklin, J., Mukhopadhyay, A., and Morgan, F.D., 2011, Hydrogeophysical methods for analyzing aquifer storage and recovery systems: Ground Water, 49, 250-269, doi10.1111/g.1745-6584. 2010.00676.x.

Minsley, B.J., Coles, D.A., Vichabian, Y., and Morgan, F.D., 2008, Minimization of self-potential survey mis-ties acquired with multiple reference locations: Geophysics, 73, F71-F81.

Morgan, F.D., Williams, E.R., and Madden, T.R., 1989, Streaming potential properties of Westerly Granite with applications: Journal of Geophysical Research-Solid Earth and Planets, 94, 12449-12461.

Ogilvy, A., Ayed, M., and Bogoslovsky, V., 1969, Geophysical studies of water leakages from reservoir: Geophysical Prospecting, 17, 36-62.

Panthulu, T.V., Krishnaiah, C., and Shirke, J.M., 2001, Detection of seepage paths in earth dams using selfpotential and electrical resistivity methods: Engineering Geology, 59, 281-295.

Petiau, G., 2000, Second generation of lead-lead chloride electrodes for geophysical applications: Pure and Applied Geophysics, 157, 357-382.

Revil, A., Pezard, P.A., and Glover, P.W.J., 1999, Streaming potential in porous media 1. Theory of the zeta potential: Journal of Geophysical Research-Solid Earth, 104, 20021-20031.

Saxton, K.E., and Rawls, W.J., 2006, Soil water characteristic estimates by texture and organic matter for hydrologic solutions: Soil Science Society of America Journal, 70, 1569-1578.

Sheffer, M.R., 2007. Forward modeling and inversion of streaming potential for the interpretation of hydraulic conditions from self-potential data, Ph.D. thesis, University of British Columbia, Vancouver, Canada.

Sill, W.R., 1983, Self-potential modeling from primary flows: Geophysics, 48, 76-86.

Sjödahl, P., Dahlin, T., and Johansson, S., 2005, Using resistivity measurements for dam safety evaluation at Enemossen tailings dam in southern Sweden: Environmental Geology, 49, 267-273.

Sjödahl, P., Dahlin, T., Johansson, S., and Loke, M.H., 2008, Resistivity monitoring for leakage and internal erosion detection at Hällby embankment dam: Journal of Applied Geophysics, 65, 155-164.

Sjödahl, P., Dahlin, T., and Zhou, B., 2006, 2.5D resistivity modeling of embankment dams to assess influence from geometry and material properties: Geophysics, 71, G107-G114.

Titov, K., Ilyin, Y., Konosavski, P., and Levitski, A., 2002, Electrokinetic spontaneous polarization in porous media: Petrophysics and numerical modeling: Journal of Hydrology, 267, 207-216.

Titov, K.V., Levitski, A., Konosavski, P.K., Tarasov, A.V., Ilyin, Y.T., and Bues, M.A., 2005, Combined application of surface geoelectrical methods for groundwaterflow modeling: A case history: Geophysics, 70, $\mathrm{H} 21-\mathrm{H} 31$.

U.S. Army Corps of Engineers, 1977, Foundation report: Hidden Dam project, Hensley Lake, Fresno River, California, Madera County, USACE, Sacramento District, Sacramento, California.

van Genuchten, M.T., 1980, A closed-form equation for predicting the hydraulic conductivity of unsaturated soils: Soil Science Society of America Journal, 44, 892-898.

\section{APPENDIX}

\section{HYDROGEOPHYSICAL MODELING}

Variably-saturated Flow Equations

The formulation of the steady-state Richards equation solved by COMSOL Multiphysics is:

$$
\nabla \cdot\left(-\frac{\mathrm{K}_{\mathrm{s}} \mathrm{k}_{\mathrm{r}}}{\rho \mathrm{g}}(\nabla \mathrm{p}+\rho \mathrm{g} \nabla \mathrm{z})\right)=\mathcal{Q}_{\mathrm{s}} \quad(\mathrm{A}-1)
$$

where $\mathrm{K}_{\mathrm{s}}$ is the saturated hydraulic conductivity $(\mathrm{m} / \mathrm{s}) ; \rho$ is the water density, which is set to a constant $1,000 \mathrm{~kg} /$ $\mathrm{m}^{3}$; $\mathrm{g}$ is the acceleration due to gravity, equal to $9.8 \mathrm{~m} / \mathrm{s}^{2}$; $\mathrm{P}$ is the state variable that describes water pressure $(\mathrm{Pa})$ throughout the model; $\mathrm{z}$ is elevation ( $\mathrm{ft}$ ); and $\mathcal{Q}_{\mathrm{s}}$ represents imposed fluid sources or sinks $(1 / \mathrm{s})$. Fixedhead boundary conditions are applied on the upstream side of the dam, with the head equal to the difference between the reservoir and ground surface elevation. On the downstream side of the dam, a mixed boundary condition is implemented to simulate the seepage face that can occur when the water level intersects the ground surface (Chui and Freyberg, 2009). The seepage face boundary condition acts as a no-flow boundary above the water level, and is assigned atmospheric pressure at locations where the water level intersects the ground surface. The left, right, and bottom boundaries of the model are placed far away from the study area to limit their influence on the simulated flow near the dam, and are assigned no-flow boundary conditions. 
Table A-1. Summary of gradation and soil-water retention data for Hidden Dam model units.

\begin{tabular}{lcccc}
\hline \hline & Impervious Core & Random Fill & Select Fill & Drainage Fill \\
\hline Saturated hydraulic conductivity (m/day) & 0.0061 & 0.30 & 0.61 & 2,438 \\
Gravel (weight fraction) & 0.10 & 0.25 & 0.30 & 1.00 \\
Sand (weight fraction) & 0.45 & 0.10 & 0.50 & 0.00 \\
Silt (weight fraction) & 0.10 & 0.63 & 0.18 & 0.00 \\
Clay (weight fraction) & 0.35 & 0.02 & Sandy loam & Sandy gravel \\
Textural classification & Sandy clay & Silty loam & 0.01 & 0.02 \\
Residual moisture (volume fraction) & 0.21 & 0.02 & 0.38 & 0.43 \\
Saturated moisture (volume fraction) & 0.42 & 0.37 & 0.8048 & 2.351 \\
a (1/m) & 0.6604 & 0.7871 & 3.3088 & 3.5952 \\
$\mathrm{n}$ & 1.9923 & 3.9218 & & \\
\hline
\end{tabular}

The van Genuchten equations (van Genuchten, 1980) are used to describe the relative hydraulic permeability, $\mathrm{k}_{\mathrm{r}}$, effective saturation, $\mathrm{Se}$, and liquid volume, $\theta$, as a function of pressure head, which is defined as $\mathrm{H}_{\mathrm{p}}=\mathrm{p} / \rho \mathrm{g}(\mathrm{m})$ :

$$
\begin{aligned}
\mathrm{k}_{\mathrm{r}}=\left\{\begin{array}{cc}
\operatorname{Se}\left(1-\left(1-\mathrm{Se}^{1 / \mathrm{m}}\right)^{\mathrm{m}}\right)^{2} & \mathrm{H}_{\mathrm{p}}<0 \\
1 & \mathrm{H}_{\mathrm{p}} \geq 0
\end{array}\right. & (\mathrm{A}-2) \\
\mathrm{Se} & =\left\{\begin{array}{ccc}
\frac{1}{\left(1+\left|\mathrm{a} \mathrm{H}_{\mathrm{p}}\right|^{\mathrm{n}}\right)^{\mathrm{m}}} & \mathrm{H}_{\mathrm{p}}<0 \\
1 & \mathrm{H}_{\mathrm{p}} \geq 0 & (\mathrm{~A}-3)
\end{array}\right. \\
\theta & =\left\{\begin{array}{ccc}
\theta_{\mathrm{r}}+\operatorname{Se}\left(\theta_{\mathrm{s}}-\theta_{\mathrm{r}}\right) & \mathrm{H}_{\mathrm{p}}<0 \\
\theta_{\mathrm{s}} & \mathrm{H}_{\mathrm{p}} \geq 0 & (\mathrm{~A}-4) \\
\mathrm{m}=1-\frac{1}{\mathrm{n}} &
\end{array}\right.
\end{aligned}
$$

Liquid volume ranges from user-specified small residual value, $\theta_{\mathrm{r}}$, to the total porosity, $\theta_{\mathrm{s}}$. These bounds, as well as the constants a and $\mathrm{n}$ depend on material properties. a is related to the air entry pressure head and desorption behavior of the soil, and $\mathrm{n}$ is related to the pore-size distribution of the soil. A detailed description of how these values were determined for the Hidden Dam model follows.

Determination of Variably Saturated Model Input Parameters

The model input parameters were obtained from the seepage studies conducted by Cedergren (1980a, 1980b) and the Soil Plant Air Water (SPAW) soils database developed by Saxton and Rawls (2006), and are available through the USDA-NRCS (http:// www.wsi.nrcs.usda.gov/products/W2Q/water_mgt/Water_
Budgets/SPAW_Model.html, last accessed January, 2010). Estimates of the saturated hydraulic conductivity (Table A-1) and gradation curves corresponding to each subdomain of the dam were provided by Cedergren (1980a) and the foundation report (U.S. Army Corps of Engineers, 1977). Grain size distributions were summarized in terms of percent gravel, sand, silt, and clay by employing a standardized grain scale.

Soil-water retention curves and saturated and residual moisture contents (Table A-1) for each subdomain were estimated using the graphical user interface of Saxton and Rawls (2006) and the available gradation data. Percentages were entered into the SPAW database to obtain estimates of textural classification (Table A-1) and statistically-based estimates of soil-water retention curves for each sub-domain. The retention curves relate matric suction $\left(\mathrm{H}_{\mathrm{p}}<0\right)$ to volumetric moisture content (volume fraction), and are a key component of the unsaturated flow models. Soil-water retention curves were created for matric suctions ranging between $1,500 \mathrm{kPa}$, corresponding to absorbed soil moisture at the residual moisture condition, and atmospheric pressure, corresponding to soil moisture at the saturated condition. The curves were produced under the assumption that the effects of organic matter and osmotic pressures were negligible. Soil compaction in the SPAW model was specified as "normal," implying that no unnatural changes in soil bulk density had occurred.

The soil-water retention curves are incorporated into the flow model by determining the parameters a and $\mathrm{n}$ in Eqs. (A-3) and (A-4) that fit each retention curve produced by the SPAW model. These parameters define the relative permeability as a function of saturation in Eq. (A-2), which is incorporated in the variably saturated flow Eq. (A-1). Nominal values a $=$ $0.6562 / \mathrm{m}$ and $\mathrm{n}=2.0$ are used for the grout curtain and bedrock as the necessary input parameters were not available for these units. 
Journal of Environmental and Engineering Geophysics

Electrokinetic Coupling to Determine the Selfpotential Response

Electrokinetic coupling is the mechanism by which fluid flow in porous media generates measurable electrical potentials in the earth, called self-potentials (Ishido and Mizutani, 1981; Morgan et al., 1989; Revil et al., 1999). A small amount of excess positive charge is transported along with fluid flow in porous materials, generating a "streaming" electric current density. Because the total electric current density in the earth must be conserved, this streaming current density generates a balancing conduction current density that flows throughout the earth. As this conduction current traverses the subsurface electrical resistivity structure, it results in measurable electrical potential differences between various locations, which are called self-potentials.

Mathematically, this phenomenon is written:

$$
\nabla \cdot\left(\mathrm{j}_{\mathrm{s}}+\mathrm{j}_{\mathrm{c}}\right)=\nabla \cdot\left(\mathcal{Q}_{\mathrm{v}} \mathrm{u}-\sigma \nabla \mathrm{V}\right)=0 \quad(\mathrm{~A}-6)
$$

where $j_{\mathrm{s}}$ and $\mathrm{j}_{\mathrm{c}}$ represent the streaming and conduction currents $\left(\mathrm{A} / \mathrm{m}^{2}\right)$, respectively. The streaming current can be defined as the excess charge density $\mathcal{Q}_{\mathrm{V}}$ in coulombs per cubic meter $\left(\mathrm{C} / \mathrm{m}^{3}\right)$ times the fluid velocity $\mathrm{u}(\mathrm{m} / \mathrm{s})$. The conduction current is defined as the negative of the electrical conductivity (ohm-m) times the electrical potential gradient $(\mathrm{V} / \mathrm{m})$. The difference in electrical potential, $\mathrm{V}$, between two locations is the self-potential value (V). No-flow boundary conditions are implemented along with Eq. (A-6), which simulates the barrier to electrical current across the air-earth interface due to the strong contrast in resistivity. The left, right, and bottom boundaries are placed far away from the dam to limit their influence on the results within the area of interest. By coupling the electrical problem to the variably saturated flow problem, the self-potential response can be calculated for any flow scenario.

Equation (A-6) can be solved in COMSOL by coupling directly to the flow velocity, $u$, that is calculated in the solution of Richards equation discussed previously. The subsurface electrical conductivity $(\sigma)$ structure is calculated dynamically as a function of the liquid volume content, $\theta$, in Eq. (A-4) using Archie's law (Archie, 1942; Lesmes and Friedman, 2005):

$$
\sigma=\sigma_{\mathrm{w}} \theta^{\mathrm{m}}
$$

where $\sigma_{\mathrm{w}}$ is the electrical conductivity of the pore water, and is fixed at a value of $0.05 \mathrm{~S} / \mathrm{m}(20 \mathrm{ohm}-\mathrm{m})$ for this study. The cementation exponent, $\mathrm{m}$, is fixed at 1.7. The excess charge density, $\mathcal{Q}_{\mathrm{V}}$, is also calculated dynamically as a function of the saturation-dependent hydraulic permeability, $\mathrm{k}$, using the relationship provided by Jardani et al. (2008):

$$
\log \left(\mathcal{Q}_{\mathrm{V}}\right)=-9.2349-0.8219 \log (\mathrm{k}) \quad(\mathrm{A}-8)
$$

